\title{
Association between intimate partner violence and utilisation of maternal health services in Nigeria
}

\author{
Bola Lukman Solanke \\ Department of Demography and Social Statistics, Obafemi Awolowo University, Ile-lfe, Nigeria \\ bsolanke@oauife.edu.ng; Tel: +234 8036313463
}

\begin{abstract}
This study examines the relationship between intimate partner violence and utilisation of maternal healthcare services. Data was extracted from the 2008 Nigeria Demographic and Health Survey. Data were analysed using the STATA. Results show that: $15.6 \%$ of the women have ever experienced at least one type of physical violence; $4.1 \%$ of the women have ever experienced at least one type of sexual violence; and $22.4 \%$ of the women have ever experienced at least one type of emotional violence. The logistic regression show that women who have ever experienced emotional violence were: $24.2 \%$ less likely to utilise skilled antenatal care $(O R=0.7578, p<0.001) ; 36.0 \%$ less likely to have facility delivery $(O R=0.6399, p<0.001)$; and $37.3 \%$ less likely to have skilled assistance during delivery $(O R=0.6272, p<0.00 I)$. The study suggested the need for a special public health programme that will focus on persons entering into marital unions at adolescence.
\end{abstract}

Keywords: Healthcare; Intimate partner; Maternal; Violence

\section{Résumé}

Cette étude examine la relation entre la violence du partenaire intime et l'utilisation des services de santé maternelle. Les données ont été extraites du Nigeria démographique 2008 et Enquête sur la santé. Les données ont été analysées en utilisant le logiciel STATA. Les résultats montrent que : $15,6 \%$ des femmes ont déjà vécu au moins un type de violence physique; $4,1 \%$ des femmes ont déjà vécu au moins un type de violence sexuelle, et $22,4 \%$ des femmes ont déjà vécu au moins un type de la violence psychologique. Le spectacle de régression logistique que les femmes qui ont déjà été victimes de violence émotionnelle étaient: $24,2 \%$ moins susceptibles d'utiliser des soins qualifiés prénatals $(O R=0,7578, p<0,001) ; 36,0 \%$ moins susceptibles d'avoir la livraison de l'installation $(O R=0,6399, p<0,001)$ et $37,3 \%$ moins susceptibles d'avoir une assistance qualifiée lors de l'accouchement $(O R=0,6272, p<0,00 I)$. L'étude suggère la nécessité d'un programme de santé publique spéciale qui mettra l'accent sur les personnes qui entrent dans une union conjugale à l'adolescence.

Mots clé: soins de santé; un partenaire intime; la mère; la violence

\section{Introduction}

Intimate partner violence is one of the forms of gender-based violence directed mainly at women because of their perceived subordinate status in the society (Heise, Ellsberg \& Goettemoller, 1999; Kishor \& Bradley, 20I2). In recent times, large numbers of scientific investigations including population-based studies have increasingly documented the prevalence and correlates of partner violence in many parts of the world (Kishor \& Johnson, 2004; Hindin, Kishor \& Ansara, 2008; ICF Macro, 20I0; Owoaje \& OlaOlorun, 2012). Recent studies have also examined its prevalence during pregnancy (Devries, Kishor, Johnson, Stockl, Bacchus, Garcia-Moreno and Watts, 2010) and its associations with other reproductive health issues such as HIV transmission (Nyamayemombe, Mishra, Rusakaniko, Benedict, Gwazame and Mukweza, 20I0) and induced abortion (Alio, Salihu, Nana, Clayton, Mbah and Marty, 20I I).

The consequences of intimate partner violence on women's reproductive health have also been brought to the fore of public health discourses by several other studies. Research evidence suggests that by limiting access and utilisation of reproductive health services and commodities, intimate partner violence increase the incidence of: unintended pregnancies; sexually transmitted infections; and negative reproductive health outcomes among women and newborns (Heise, Ellsberg \& Gottemoeller, 2002; Population Reference Bureau [PRB], 2010; United Nations Fund for Population 
Activities [UNFPA], 2012; World Health Organisation [WHO], 20I2).

In Nigeria, the 2008 Nigeria Demographic and Health Survey (NDHS) provided national estimates of the prevalence of intimate partner violence. Findings from the survey revealed that among ever married women, $18 \%$ have ever experienced physical violence from either current or former partner with $16 \%$ of them reporting being ever slapped as the common type of physical violence ever experienced; $4 \%$ of the women had experienced sexual violence; and $24 \%$ had experienced emotional violence with $17 \%$ of them reporting being ever insulted or made feel bad as the dominant type of emotional violence ever experienced (National Population Commission [NPopC] \& ICF Macro, 2009).

As part of efforts to improve women's reproductive health in the country, intimate partner violence and other types of gender-based violence was acknowledged by the 2004 National Population Policy for Sustainable Development (NPopC, 2004) and the 2006 National Gender Policy not only as a violation of women's fundamental human rights, but also as an impediment to women's reproductive health. The Gender Policy for the Nigeria Police Force (2010) and Gender-based Violence (Prohibition) Law now been adopted in many State of the federation are parts of contemporary gender responsive policies to further promote women's health in the country (Omoluabi, Aina and Attanasso, 2014). Recent studies in Nigeria (Esere, Adeyemi, Durosaro \& Omotosho, 2009; Antai, 2011; Yusuf, Arulogun, Oladepo \& Olowokeere, 20I I; Okemiri \& Adekola, 20I2) have also provided evidence of the consequences of partner violence on women's reproductive health in the country.

However, in contrast to several studies in other climes (for instance Stewart, Sommerfelt, Borwankar, Oluwole, Fogg, and Goings (2010) that have specifically explored the associations between partner violence and maternal health, few studies in Nigeria have focused on the link between partner violence and utilisation of maternal healthcare services in the country. The objectives of this study are therefore to: (i) further assess the prevalence of intimate partner violence; and (ii) ascertain the association between intimate partner violence and utilisation of maternal healthcare services among ever married women in the country. This is with the view to providing additional information needed to boost public information and education about intimate partner violence in Nigeria.

\section{Literature Review and Theoretical Framework}

Violence against women gained global prominence after the 1994 Cairo International Conference on Population and Development (ICPD). In 1995, the Beijing Declaration and Platform for Action recognised violence against women as one of the 'critical areas of concern' in the promotion of gender equality, development and peace (United Nations [UN], 1995). In one of the early efforts geared towards boosting global awareness about violence against women, the WHO (2002) reviewed 35 selected population-based studies carried out between 1982 and 1999 across the world. Findings from the review showed that the prevalence of ever being physically assaulted by a partner was highest in Nicaragua (52\%) and lowest in Paraguay and the Philippines (10\%).

Empirical evidence of the linkages between partner violence and reproductive health outcomes were provided by the Demographic and Health Survey (DHS) programme in a multi-country study conducted between 1995 and 2002 (Kishor \& Johnson, 2004). The study collected wide spectrum data on domestic and intimate partner violence in nine developing countries, namely, Cambodia, Colombia, Dominican Republic, Egypt, Haiti, India, Nicaragua, Peru, and Zambia. Using either the single-question threshold approach or the modified conflict tactics scale (CTS) earlier developed by Straus (1979) in the measurement of intrafamily conflict and violence, valid data was generated on different forms of partner violence, namely, physical, sexual, and emotional violence and controlling behaviours by male partners (marital control).

In the study, the proportions of women who have ever experienced any type of physical violence ranged from $16.4 \%$ in Cambodia to $40.0 \%$ in Colombia. Within the last year preceding the survey, prevalence of physical violence ranged from II.9\% in Nicaragua to $14.6 \%$ in Cambodia. Sexual violence among ever married women was found to be highest in Haiti with $17.0 \%$ prevalence rate and lowest in Cambodia with $3.6 \%$ prevalence rate. Also, women's experiences of at least one type of emotional violence ranged from II.5\% in Colombia to $29 \%$ in Nicaragua.

The Kishor and Johnson study further revealed key risk factors for ever experiencing any form of partner violence in the countries studied. Though the results showed varying degrees of significance in the countries, the significant factors that cut across more than half of the countries include: women's 
characteristics (such as number of unions, number of children, education and work status); husband's characteristics (such as husband's drunkenness and education); and relationship factors (such as spousal age and educational difference); and community/societal factors. However, poverty, a key community/societal factor was not found to be a significant risk factor in the study.

Among other demographic and health outcomes investigated in the study, a weak and inconsistent relationship was found between partner violence and maternal healthcare. In all countries studied except Cambodia, women who have never experienced partner violence had higher utilisation of antenatal care. However, this relationship was weakened by unequal level of access to antenatal care in the countries studied (Kishor \& Johnson, 2004). In Haiti, Nicaragua, Peru and Zambia, women who had ever experienced partner violence had higher proportions of deliveries assisted by skilled health personnel, while the reverse was the case in other countries studied.

In response to the earlier call of the Beijing Declaration and Platform for Action, the WHO in 1997 commenced a multi-country study on women's health and domestic violence against women in 10 countries, namely, Bangladesh, Brazil, Ethiopia, Japan, Namibia, Peru, Samoa, Serbia and Montenegro, Thailand, and United Republic of Tanzania (WHO, 2005). The WHO Study was aimed at filling identified gaps in international research on violence against women. The measurement of different forms of partner violence in the WHO Study was similar to the Kishor and Johnson study. However, unlike the study by Kishor and Johnson, the WHO Study used a single methodology (CTS) across all the countries studied and also investigated women's attitudes towards violence. Findings from the $\mathrm{WHO}$ Study revealed that the proportions of women who had ever experienced any type of physical violence from a male partner was lowest in Japan with 13\% prevalence rate and highest in Peru with $61 \%$ prevalence rate. Sexual violence was found to be lowest in Japan and Serbia and Montenegro with 6\% prevalence rate and highest in Ethiopia with 59\% prevalence rate.

The WHO study buttressed linkages between partner violence and women's utilisation of reproductive health services. In most countries studied, there were no differences in the utilisation of antenatal care services by women who have ever or never experienced partner violence. However, in
Bangladesh, Ethiopia, and Tanzania, women who have ever experienced partner violence were found to have less likelihood for the utilisation of antennal care services during their most recent pregnancy. This was consistent with findings in a latter study by Hindin, Kishor \& Ansara (2008).

The study by Hindin et al. (2008) focused on both women and couples unlike the study by Kishor \& Johnson (2004) and the WHO Study. In the study which was conducted in 10 developing countries, it was found that women who have ever experienced partner violence in Bangladesh, Dominican Republic and Zambia were less likely to seek antenatal care within the first trimester of pregnancy. Similarly, in Bangladesh, Kenya, Rwanda and Zimbabwe, women who have ever experienced partner violence were less likely to have facility delivery. These finding were incongruous with findings in another study conducted in sub-Saharan Africa to exclusively explore the associations between domestic violence and maternal health by Stewart et al. (2010).

The study by Stewart et al. (2010) found that in Zambia, women's experienced of physical/sexual violence from a partner was not associated with use of antenatal care, skilled delivery and delivery in a facility. However, the finding of Stewart et al. (2010) was consistent with findings in a recent study in Nepal by Tuladhar, Khanal, Lila, Ghimire \& Onta (20I3). In the study, $53 \%$ of the women with recent live births who experienced physical or sexual violence by male partners were 13\% more likely to make at least four antenatal visits during their last pregnancy than women who have never experienced physical or sexual violence. The study further found that $42 \%$ of women who experienced partner violence were $10 \%$ more likely to have skilled delivery than women who never experienced partner violence. Thus, empirical research evidence has established varying degrees of intimate partner violence prevalence in many parts of the world. The harmful consequences of partner violence on women's health are no longer in doubt. However, inconsistency persists on the influence of partner violence on utilisation of maternal care services.

Virtually all literature examined situated the causes and risk factors for intimate partner violence within the framework of the ecological model. The model which was first applied by Belsky (1980) for understanding child abuse and neglect, asserts that domestic and intimate partner violence are multifaceted phenomena significantly influenced by the interplay of four-level factors, namely: individual factors (such as young age, level of education, and 
harmful drug use); relationship factors (such as male dominance of family, and disparity in partner's educational attainment); and community and societal factors such as poverty, social and economic status, and weak community sanctions against partner violence (Heise, 1998; WHO, 2012).

The interplay of the four-level factors impacts on utilisation of maternal healthcare through different form of intimate partner violence. Hence, the ecological model underpinned this study. Previous studies such as Heise et al. (1999); Kishor \& Johnson, (2004); WHO, 2002; 2005; 2012) have also used the ecological model to explained domestic and partner violence. The four-level factors identified in the ecological model were controlled in the current analysis to show variation in utilisation of maternal healthcare solely attributable to intimate partner violence. However, three variables, namely, age at first marriage, place of residence, and women's attitude to partner, were selected as intervening variables in the study. These variables have been found in different countries to be associated with perpetration of violence against women (WHO, 2005; 2012).

\section{Data and Methods}

\section{Data Source}

The data analysed in this study was extracted from the 2008 NDHS. The 2008 NDHS is the fifth round of the worldwide DHS programme which has been conducted every five years in the country since 1990 except in 1994 due to political turbulence. The basic objective of the 2008 NDHS was to provide reliable estimates of basic demographic characteristics such as fertility, mortality, contraceptive prevalence and selected reproductive health indicators (NPopC \& ICF Macro, 2009). The survey used a stratified twostage cluster design consisting of 888 clusters (286 urban, 602 rural) to select approximately 36,800 households in which eligible women aged 15-49 years were selected for the survey. The 2008 NDHS is expected to be updated by the just concluded 2013 survey.

\section{Sample Size}

The 2008 NDHS provided information on 33,385 women sampled across Nigeria. However, some of the women were not included in the present study. All the women not selected for the questions in the domestic violence module (9,633 women) were excluded since information on gender-based violence were not sourced from them. Selected women who were not married as at the time of the survey (4,363 women) were also excluded from analysis since they did not fall within the category of 'ever married' women. The study therefore analysed a weighted sample size of 16,763 women.

\section{Outcome Variable}

The outcome variable of the study is maternal healthcare utilisation which is measured by utilisation of three maternal healthcare indicators, namely antenatal care, place of delivery and assistance during delivery. With the exclusion of postnatal care, these indicators are central to maternal health measures and well reported in the 2008 NDHS National Report. Each service was dichotomised to indicate adequacy or otherwise of maternal health status. Antenatal care services provided by doctor, nurse/midwife and auxiliary nurse/midwife was defined as 'skilled antenatal care' while antenatal care services provided by other providers such as community health workers and traditional birth attendants was defined as 'unskilled antenatal care' in line with the 2008 NDHS classification of skilled and unskilled antenatal care (NPopC and ICF Macro, 2009). Deliveries in public or private health hospital/clinics was defined as 'facility delivery' while deliveries elsewhere was defined as 'non facility delivery'. Deliveries assisted by a doctor, nurse, midwife, or auxiliary nurse/midwife were defined as 'skilled delivery' while deliveries assisted by other personnel was defined as 'unskilled delivery'.

\section{Explanatory Variables}

The explanatory variables in the study are physical, sexual and emotional violence. In the $2008 \mathrm{NDHS}$, data on intimate partner violence were created by asking women to respond 'yes' or 'no' to questions depicting specific type of partner violence. In the case of physical violence, women responded to questions such as: did husband/partner ever slap you?; did husband/partner ever twist your arm or pull hair?; did husband/partner ever push you, shake you, or throw something at you?; did husband/partner ever punch you with his fist or with something that could hurt you?; did husband/partner ever kick you, drag you or beat you up?; did husband/partner ever try to choke you or burn you on purpose?; and did husband/partner ever threaten or attack you with a knife, gun or any other weapon?

In the case of sexual violence, women responded to questions such as: did husband/partner ever physically force you to have sexual intercourse with him when you did not want it or force you to perform any sexual act when you did not want to? With respect to emotional violence, women responded to questions on whether 
husband/partner ever: say or do something to humiliate you in front of others; threaten to hurt or harm you or someone close to you; or insult you or make you feel bad about yourself? Using the Stata 'generate and replace' command, each type of partner violence was aggregated into a single variable reflecting three specific intimate partner violence, namely, physical, sexual, and emotional violence by a male partner.

\section{Data Analysis}

Data were analysed at the univariate, bivariate and multivariate levels using STATA after adjusting for sampling errors by the application of the 'svyset' commands. At the univariate level, the characteristics of women who answered the domestic violence question were described using frequency distributions. Prevalence of intimate partner violence was described using bar chart. At the bivariate level, maternal healthcare utilisation was cross tabulated with each type of intimate partner violence based on the number of ever married women who had at least one live birth during the five years preceding the survey and who answered the domestic violence question. The chisquare statistic was used to examine statistical significance of the association between intimate partner violence and utilisation of maternal healthcare services.

Any non significant variable identified in the chisquare test was removed from further analysis. This was done to remove any spurious association between the variables. The binary logistic regression was performed to examine the simultaneous effect of partner violence on utilisation of maternal healthcare. The logistic regression was replicated in two models. The first model (unadjusted odds) regressed utilisation of maternal healthcare on partner violence and the sets of intervening variables. The second model (adjusted odds) regressed utilisation of maternal healthcare only on partner violence. In the second model, the regressions were run separately for each type of partner violence. However, both models controlled for the four-level factors of the ecological model.

The logistics command in STATA as applied in this study fits a logistic regression model of utilisation of maternal healthcare on partner violence and the intervening variables where utilisation of maternal healthcare is a $0 / I$ variable, with " $I$ " indicating utilisation of adequate maternal healthcare and " 0 " otherwise. The logistic displays estimates of likelihood of utilisation as odds ratio (StataCorp
2009). The full logistic regression model constructed for analysis is written as:

$\log i t[\pi(x)]=\beta_{0}+\beta_{p h y}+\beta_{\text {sev }}+\beta_{\text {emv }}+\beta_{\text {res }}+\beta_{\text {agefm }}+\beta_{w j v}$

where phy $=$ physical violence

sev $=$ sexual violence

emv $=$ emotional violence

$\mathrm{x}=$ utilisation of maternal healthcare

services

res $=$ place of residence

agefm $=$ age at first marriage

wjv $=$ women' $s$ attitude to domestic

violence

$\pi(x)$ represents the probability of utilisation of maternal healthcare services

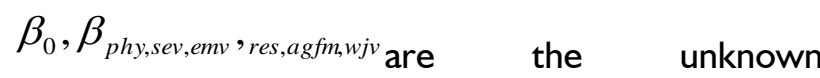
parameters of the model estimated by maximum likelihood technique in the STATA software.

\section{Data Limitations}

The data analysed in the study was extracted from a cross-sectional survey which is not sufficient to establish causality between intimate partner violence and utilisation of maternal healthcare services. Also, analysis carried out assumed no bias in women's reporting of partner violence. However, in line with the observations by Garcia-Moreno \& Stockl (2013) and Uwameiye \& Iserameiya (2013) that violence is under-reported worldwide, there exist a possibility that some of the sampled women failed to report experiences of partner violence. This translates to the possibility of higher prevalence of partner violence in the study population than reported or analysed in the study.

\section{Results}

\section{Sample characteristics}

Table I show results of selected socio-economic characteristics of respondents. Nearly half of the respondents $(46.7 \%)$ had no formal education. The proportions of the women who attained either primary or secondary education were similar ( $22.5 \%$ vs $23.6 \%$ ). Only $7.2 \%$ of the women had attained higher education. Nearly one-third (32.7\%) of the women were not currently working as at the time of the survey. A majority (44.3\%) were in the lowest household wealth group. However, the proportion of women in the 'middle' household wealth group was significant (36.7\%). The proportion of women in the 'highest' wealth group was lowest in the sample. 
Table I: Distribution of respondents by selected socioeconomic characteristics, Nigeria 2008

\begin{tabular}{|c|c|c|}
\hline Variable & Number of Women & Percent \\
\hline \multicolumn{3}{|l|}{ Education } \\
\hline None & 7,891 & 46.7 \\
\hline Primary & 3,775 & 22.5 \\
\hline Secondary & 3,950 & 23.6 \\
\hline Higher & $\mathrm{I}, 207$ & 7.2 \\
\hline \multicolumn{3}{|l|}{ Employment } \\
\hline Not working & 5,477 & 32.7 \\
\hline Working & $\mathrm{II}, 286$ & 67.3 \\
\hline \multicolumn{3}{|l|}{ Place of residence } \\
\hline Urban & 5,289 & 31.5 \\
\hline Rural & $1 \mathrm{I}, 474$ & 68.5 \\
\hline \multicolumn{3}{|l|}{ Age at first marriage } \\
\hline 14 years or less & 4,511 & 26.9 \\
\hline 15-24 years & $|0,47|$ & 62.5 \\
\hline $25-34$ years & $\mathrm{I}, 707$ & 10.2 \\
\hline 35 years and above & 74 & 0.4 \\
\hline \multicolumn{3}{|l|}{ Household wealth group } \\
\hline Lowest & 7,426 & 44.3 \\
\hline Middle & 6,146 & 36.7 \\
\hline Highest & 3,190 & 19.0 \\
\hline \multicolumn{3}{|c|}{ Attitude to domestic violence } \\
\hline Do not accept violence & 14,634 & 87.3 \\
\hline Accept violence & 2,128 & 12.7 \\
\hline \multicolumn{3}{|l|}{ Attitude to wife-beating } \\
\hline Do not justify on any reason & 8,459 & 50.5 \\
\hline Justify on some reasons & 8,304 & 49.5 \\
\hline \multicolumn{3}{|l|}{ Partner's alcohol consumption } \\
\hline Not drinking & 13,589 & 81.1 \\
\hline Drinks & 3,173 & 18.9 \\
\hline \multicolumn{3}{|l|}{ Partner's education } \\
\hline None & 6,673 & 39.8 \\
\hline Primary & 3,532 & 21.1 \\
\hline Secondary & 4,517 & 26.9 \\
\hline Higher & 2,041 & 12.2 \\
\hline \multicolumn{3}{|l|}{ Partner's age } \\
\hline 24 years or less & 444 & 2.7 \\
\hline $25-34$ years & 4,012 & 23.9 \\
\hline 35 years and above & 12,307 & 73.4 \\
\hline Total & 16,763 & 100.0 \\
\hline
\end{tabular}

\section{Source: 2008 NDHS}

Overwhelming majority of the women (87.3\%) does not justify domestic violence on the basis that the women refuses to have another child or fails to prepare food on time. However, almost half of the women $(49.5 \%)$ believed that wife-beating was justified for various reasons. The distribution of the respondents by partner's characteristics revealed that majority of the women partner's (81.1\%) does not consume alcohol; only $18.9 \%$ of the women's partners consume alcohol. More than one-third $(39.8 \%)$ of the partner's had no formal education.
However, $21.1 \%$ and $26.9 \%$ of them had attained primary and secondary education respectively. Only $12.2 \%$ of the partners had attained higher education. A majority of the respondents' partners (73.4\%) are 35 years or older.

\section{Prevalence of Intimate Partner Violence}

Figure I shows women's experiences of intimate partner violence. As shown in the chart, $15.6 \%$ of the women had experienced at least one type of physical violence with being ever slapped by a male partner as the dominant type of physical violence 
ever experienced by the women. Sexual violence was less common among the women. Only $4.1 \%$ of the women had ever been forced to have any type of sexual act against her volition, with $3.5 \%$ of them being ever forced to have sexual intercourse with male partner when not wanted. Emotional violence was more reported by the women. At least one type of emotional violence was experienced by $22.4 \%$ of the women with being ever insulted or made to feel bad being the dominant type of emotional violence experienced among the women.

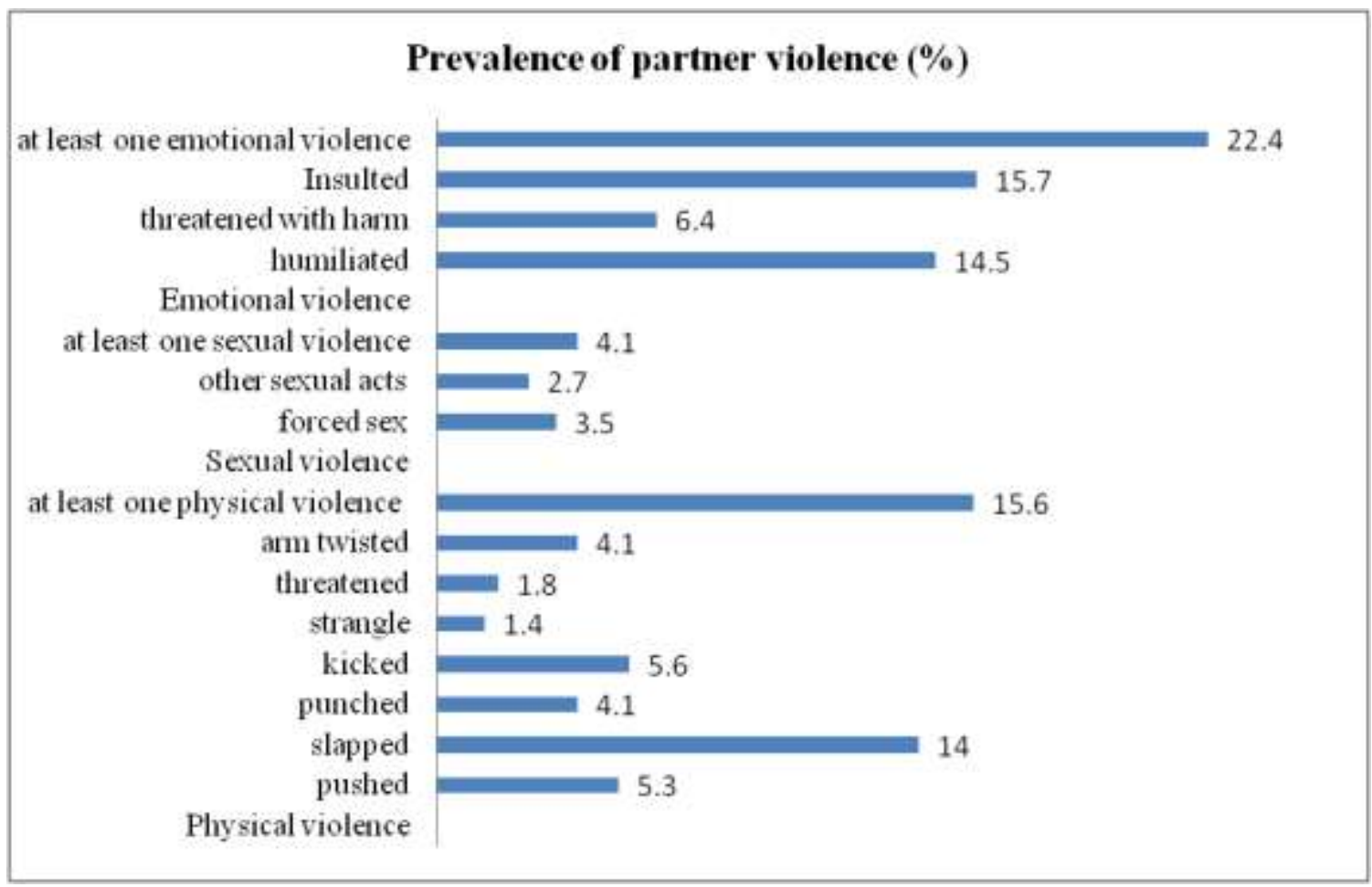

\section{Figure I: Prevalence of Intimate Partner Violence}

\section{Utilisation of Maternal Healthcare Services}

Utilisation of maternal healthcare services was analysed with respect to the most recent live birth. Among the 16,763 women analysed in the study, I I,689 of them have had at least one live birth in the five years preceding the survey. As shown in Figure $2,56.8 \%$ of the women received skilled antenatal care during their most recent pregnancy, while
43.2\% received unskilled antenatal care, implying that substantial proportion of the women missed the opportunity of benefitting from essential preventive care delivered through the current focused antenatal care programme in the country. 


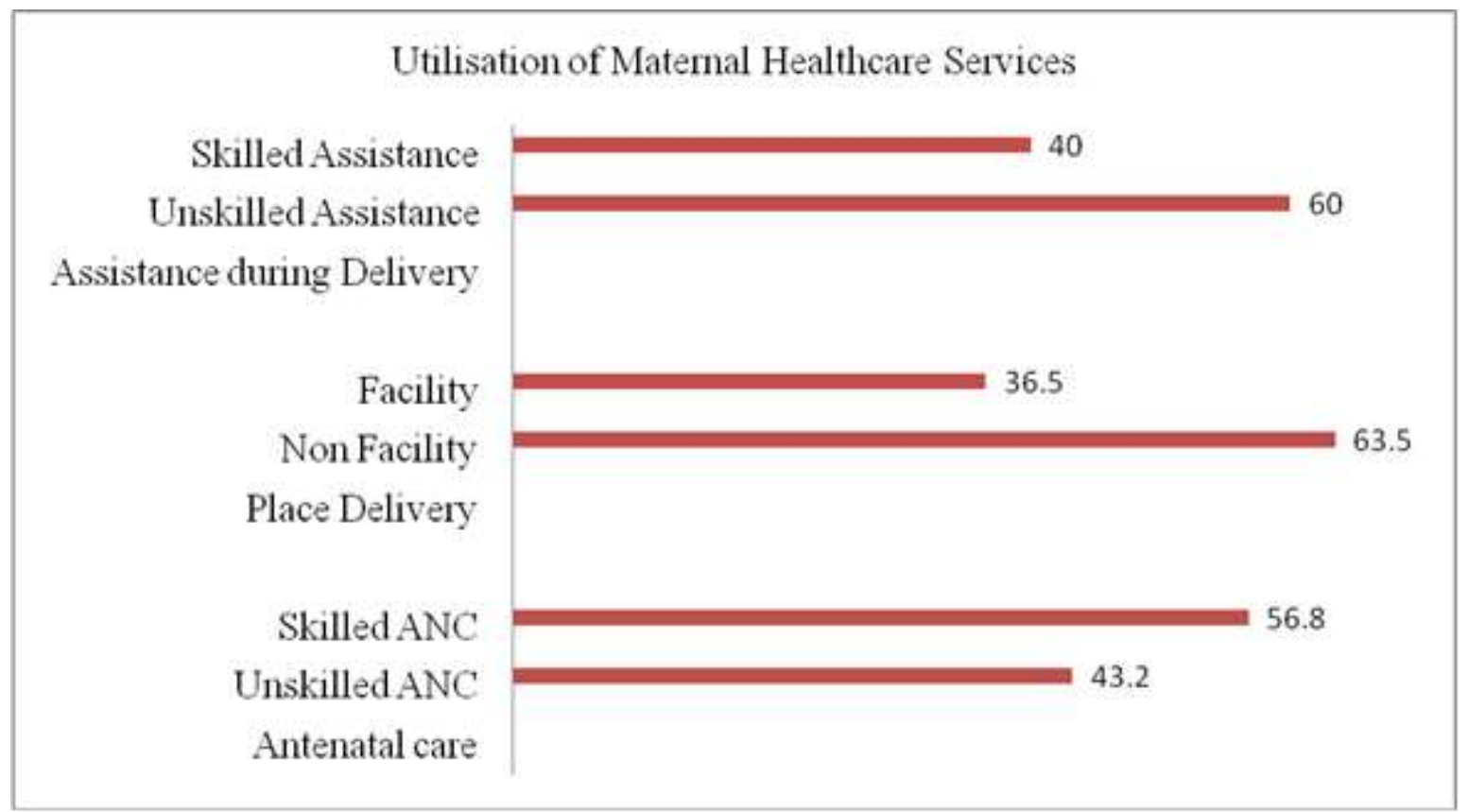

Figure 2: Utilisation of Maternal Healthcare Services (\%)

More than two-thirds (63.5\%) of the most recent child deliveries among the women took place at non health facility, compared with the $36.5 \%$ facility delivery among the women. This result was corroborated by the distribution of the women by type of assistance during delivery since non facility deliveries is almost tantamount to the absence of a trained birth attendant during delivery. As shown in the chart, $60.0 \%$ of the women received unskilled assistance during their most recent delivery compared with $40.0 \%$ who received skilled assistance. These results depict a poor level of utilisation of maternal healthcare services among the respondents.

The relationship between intimate partner violence and utilisation of maternal healthcare services is shown in Table 2. Though, physical violence was significantly associated with antenatal care, place of delivery, and assistance during delivery, the respondents irrespective of experience of physical violence only had higher utilisation of skilled antenatal care. The proportions of respondents who had facility delivery and skilled assistance were consistently lower irrespective of ever or never experiencing any type of physical violence. This pattern was consistent with respondents' experience of sexual and emotional violence. However, sexual violence did not show significant statistical association with any of the maternal healthcare indicators. Sexual violence was thus dropped from further analysis. 
Table 2: Percentage of women with recent live births by utilisation of maternal healthcare services, according to experiences of Intimate Partner Violence, Nigeria 2008

\begin{tabular}{|c|c|c|c|c|}
\hline Variable & $\begin{array}{l}\text { Antena } \\
\text { Skilled }\end{array}$ & $\begin{array}{l}\text { atal care } \\
\text { Unskilled }\end{array}$ & $\begin{array}{l}\text { Place of Delivery } \\
\text { Facility Non Facility }\end{array}$ & $\begin{array}{l}\text { Delivery Assistance } \\
\text { Skilled Unskilled }\end{array}$ \\
\hline \multicolumn{5}{|l|}{ Physical Violence } \\
\hline Never experienced & 55.7 & 44.3 & 64.4 & 38.8 \\
\hline \multirow[t]{2}{*}{ Ever experienced } & 63.2 & 36.8 & $4 I .4 \quad 58.6$ & $46.5 \quad 53.5$ \\
\hline & \multicolumn{2}{|c|}{$\chi^{2}=41.3, p<0.05$} & $\chi^{2}=26.7, p<0.05$ & $\chi^{2}=45.5, p<0.05$ \\
\hline \multicolumn{5}{|l|}{ Sexual Violence } \\
\hline Never experienced & 56.8 & 43.2 & 36.6 & 60.0 \\
\hline \multirow[t]{2}{*}{ Ever experienced } & 57.9 & 42.1 & 33.4 & 39.1 \\
\hline & \multicolumn{2}{|c|}{$\chi^{2}=0.2, p=0.6885$} & $\chi^{2}=2.5, p=0.2235$ & $\chi^{2}=0.21, p=0.7189$ \\
\hline \multicolumn{5}{|l|}{ Emotional Violence } \\
\hline Never experienced & 57.6 & 42.4 & 62.0 & 58.5 \\
\hline \multirow[t]{2}{*}{ Ever experienced } & 54.3 & 45.7 & 68.6 & 34.9 \\
\hline & \multicolumn{2}{|c|}{$\chi^{2}=11.0, p<0.05$} & $\chi^{2}=45.9, p<0.05$ & $\chi^{2}=44.6, p<0.05$ \\
\hline
\end{tabular}

\section{Multivariate analysis}

Table 3 show results of the binary logistic regression analysis of maternal healthcare utilisation. There were significant disparities in the influence of physical and emotional violence on utilisation of maternal healthcare services. In Model I, on the one hand, women who have ever experienced physical violence were $51.1 \%$ more likely to utilise skilled antenatal care $(O R=1.5109, \mathrm{p}<0.00 \mathrm{I}) ; 56.3 \%$ more likely to have facility delivery $(O R=1.5653$, $\mathrm{p}<0.00 \mathrm{I}$ ); and $71.5 \%$ more likely to utilise skilled assistance $(O R=1.7154, p<0.00 I)$ than women who have never experienced any type of physical violence by a male partner. On the other hand, respondents who have ever experienced emotional violence were $10.8 \%$ less likely to utilise skilled antenatal care $(O R=0.8922, p>0.005) ; 25.3 \%$ less likely to have facility delivery $(O R=0.7468$, $\mathrm{p}<0.00 \mathrm{I}$ ); and $27.2 \%$ less likely to utilise skilled assistance $(O R=0.7280, p<0.00 \mathrm{I})$ compared with women who have never experienced any type of emotional violence by a male partner. 
Table 3: binary logistic regression examining influence of physical and emotional violence on utilisation of maternal healthcare services

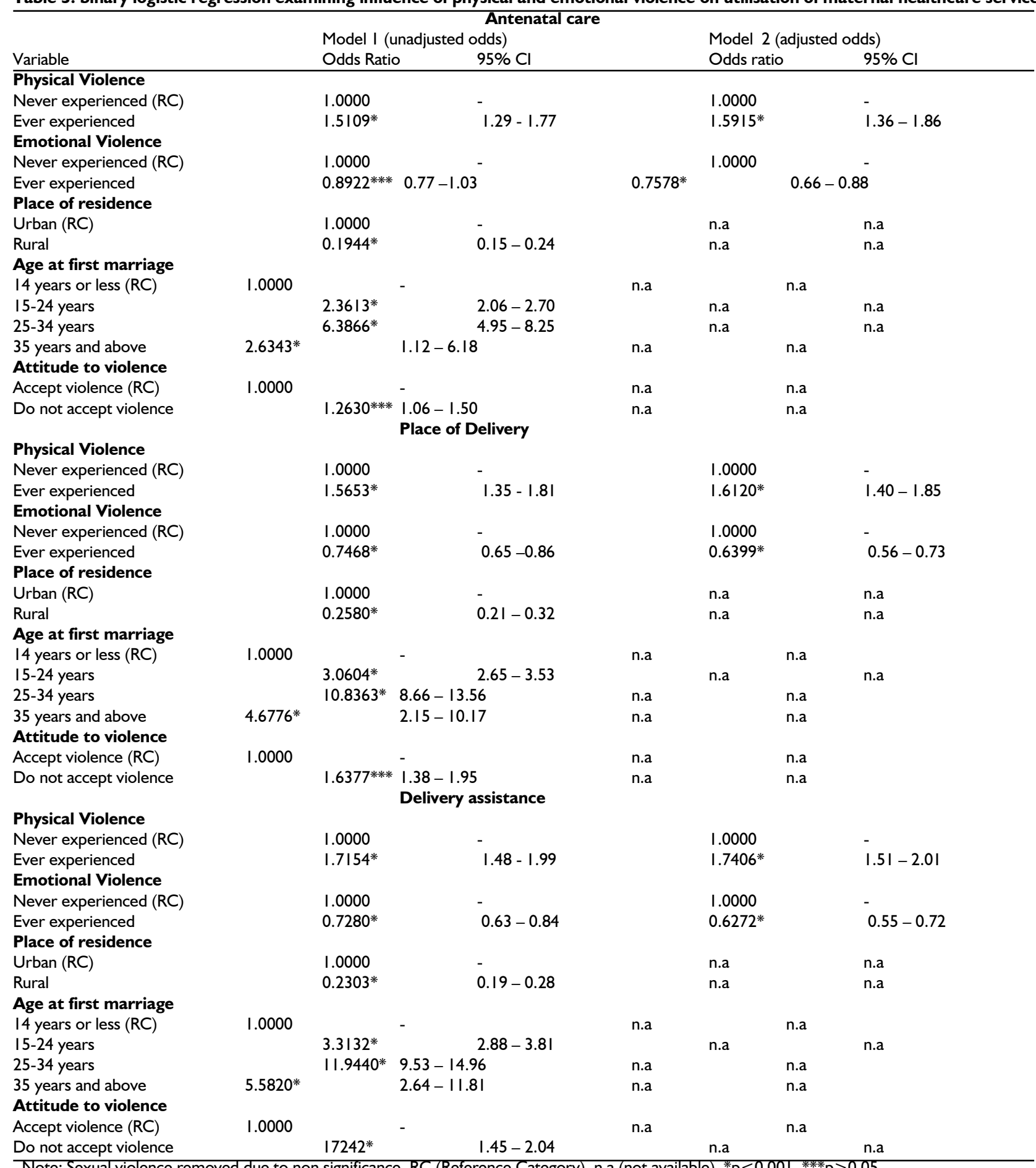

Note: Sexual violence removed due to non significance, RC (Reference Category), n.a (not available), ${ }^{*} \mathrm{p}<0.001,{ }^{* * * *} \mathrm{p}>0.05$

In the model, place of residence, age at first marriage and women's attitude to domestic violence showed significant influence on utilisation of maternal health services. For instance, rural women were $80.6 \%$ less likely to utilise skilled antenatal care $(O R=0.1944, p<0.00 \mathrm{I}) ; 74.2 \%$ less likely to utilise facility delivery $(O R=0.2580, p<0.00 \mathrm{I})$; and $77.0 \%$ less likely to utilise skilled assistance $(O R=$ $0.2303, p<0.001)$. Similarly, utilisation of maternal health services increase significantly as age at first marriage increase from 14 years or less to 15-24 years and 25-34 years. Despite slight decline in likelihood of utilisation at ages 35 years and above, the extent of utilisation of maternal services more than double the level of utilisation at ages 14 years or less. Women who do not accept violence consistently had higher likelihood of utilising maternal health services than women who accepted domestic violence.

Controlling for place of residence, age at first marriage and women's attitude to domestic violence in Model 2, results show that though partner violence remains a strong influence on utilisation of maternal health services, there were no change in the pattern of influence on utilisation of maternal health services. Higher utilisation of maternal health 
services remain associated with women's experience of physical violence, while emotional violence remained associated with lower utilisation of maternal health services. For instance, respondents who have ever experienced physical violence were $59.1 \%$ more likely to utilise skilled antenatal care $(O R=1.5915, \mathrm{p}<0.00 \mathrm{I}) ; 61.2 \%$ more likely to have facility delivery $(O R=1.6120$, $\mathrm{p}<0.00 \mathrm{I}$ ); and $74.1 \%$ more likely to utilise skilled assistance $(\mathrm{OR}=1.7406, \mathrm{p}<0.00 \mathrm{I})$ than women who have never experienced any type of physical violence by a male partner. Similarly, respondents who have ever experienced emotional violence were $24.2 \%$ less likely to utilise skilled antenatal care $(O R=0.7578, p<0.00 I) ; 36.0 \%$ less likely to have facility delivery $(O R=0.6399, p<0.00 \mathrm{I})$; and $37.3 \%$ less likely to utilise skilled assistance $(\mathrm{OR}=$ $0.6272, p<0.00$ I) compared with women who have never experienced any type of emotional violence by a male partner.

\section{Discussion and Conclusion}

In this study, we assessed the prevalence of intimate partner violence and ascertained its association with utilisation of maternal healthcare services. Findings from the study were consistent with earlier estimates in WHO 2002; Kishor \& Johnson, 2004; and ICF Macro 2010. However, prevalence rates of physical violence (18\% vs $15.6 \%)$ and emotional violence $(24 \%$ vs $22.4 \%)$ violence as found in the study were slightly lower than the reported rates in the 2008 NDHS. The prevalence rate of $4.1 \%$ sexual violence found in the study was similar to the $4.0 \%$ reported in the 2008 NDHS (NPopC \& ICF Macro, 2009).

The study in line with findings in Kishor \& Johnson (2004) found an inconsistent relationship between intimate partner violence and utilisation of maternal healthcare services. However, unlike the finding of Kishor \& Johnson in Cambodia where women who have never experienced partner violence had higher utilisation of skilled antenatal care, this study, consistent with the WHO Study found high utilisation of skilled antenatal care among respondents irrespective of whether they have ever or never experience any type of physical violence.

Unlike in the study by Stewart et al. (2010) where it was found that having experienced of physical/sexual violence from a partner was not associated with the use of antenatal care, skilled delivery and facility delivery, this study consistent with Tuladhar et al. (2013) found that women who have ever experienced physical violence were more likely to utilise skilled antenatal care, facility delivery and skilled assistance during delivery. Though, this is incongruous with human expectation, we cannot rule out the possibility that women who experience physical partner violence are likely to visit health facilities for treatment and management of injuries especially if serious injuries results from partner brutality. Such visits may provide ample opportunity for medical counselling and education that may later influence utilisation of maternal healthcare services.

It is also possible that age at first marriage catalyses utilisation of maternal health services as women entering marital unions at older ages are likely to have become more aware of women's need for daily healthy living particularly during pregnancy and after child birth. Such awareness increase women's utilisation of maternal health services. Considering the fact that most abused women maintain the hope that their violent partners will change with time, older women may also adopt health facility utilisation as a coping strategy to maintaining safety for mother and child in violent relationships. It is therefore important to have a special public health programme that that will focus on persons starting marital unions during adolescence. Couples need to be encouraged to abstain from any type of violence against women.

This study, consistent with finding in Hindin, Kishor \& Ansara (2008), also found that women who have ever experienced emotional violence by a male partner have less likelihood for the utilisation of skilled antenatal care, facility delivery and skilled assistance. It is possible that the link between emotional violence and utilisation of maternal health services is due to the fact that a lot of women considered psychological abuse by male partners as more debilitating than physical violence. A woman experiencing constant verbal insults and humiliation from a male partner more often than not feels unloved, unwanted and powerless to take full control of her sexual and reproductive health. This feeling may hinder utilisation of maternal health services, particularly if the permission of the male partner is required to access healthcare or if the male partner is the one to provide money for healthcare consultation and treatment. Thus, emotional violence may be playing salient but unnoticed role in the poor utilisation of maternal health services among women. Efforts to boost utilisation of maternal health services should 
therefore pay more attention to addressing emotional violence as well as other forms of violence against women.

The study not only provided evidence that intimate partner violence is associated with utilisation of maternal healthcare services, it also buttressed the need for a special public health programme to focus on young persons starting marital unions. The utilisation of maternal health services in the country may remain poor if efforts are not made to address the prevalence of intimate partner violence.

\section{Acknowledgements}

The author appreciates and thanks the National Population Commission (NPopC) [Nigeria], ICF Macro and MEASURE DHS Project not only for the collection of the NDHS datasets, but also for making the datasets available for use.

\section{References}

Alio, A. P., Salihu, H. M., Nana, P. N., Clayton, H. B., Mbah, A. K., and Marty, P. J. 20II. "Association between intimate partner violence and induced abortion in Cameroon", International Journal of Gynecology and Obstetrics I I 2: 83-87.

Antai, D. 201I. "Controlling behaviour, power relations within intimate relationships and intimate partner physical and sexual violence against women in Nigeria”, BMC Public Health. Retrieved June 25, 2013 from http://www.biomedcetral.com/I47I2458/ I I/5 I I.pdf.

Belsky, J. 1980. "Child maltreatment: An ecological integration", American Psychologist 35: 320-335. Retrieved September 25, 2013 from www.researchgate.net/publication/I58I2067 Ch ild_maltreatment_An_Ecological_Integration/file/ 504635193b554a09 Ic.pdf

Devries, K. M., Kishor, S., Johnson, H., Stockl, H., Bacchus, L. J., Garcia-Moreno, C., and Watts, C. 2010. "Intimate partner violence during pregnancy: analysis of prevalence data from 19 countries", Reproductive Health Matters 18(36): I58-170.

Esere, M. O., Adeyemi, I. I., Durosaro, I. A., and Omotosho, J. A. 2009. "Causes and consequences of intimate partner rape and violence: Experiences of victims in Lagos, Nigeria", Journal of AIDS and HIV Research I(I): I7.
Garcia-Moreno, C., and Stockl, H. 20I3. "Violence against Women, Its Prevalence and Health Consequences", In Garcia-Moreno, C. \& Riecher-Rossier, A. (eds). Gender Violence and Mental Health. Geneva: World Health Organisation.

Heise, L. L. 1998. "Violence Against Women: An Integrated, Ecological Framework", Violence Against Women, 4(3): 262 - 290. Retrieved September 25, 2013 from http://gbvor.net/wpcontent/uploads/2012/10/violence.against.women .an.integrated.ecological.framework-Heise1998.pdf

Heise, L., Ellsberg, M., and Gottemoeller, M. 1999. "Ending Violence Against Women", Population Reports, L(II), Baltimore, Johns Hopkins University School of Public Health, Population Information Program.

Heise, L., Ellsberg, M., and Gottmoeller, M. 2002. "A global overview of gender-based violence", International Journal of Gynecology and Obstetrics 78 Suppl. I, S5-SI4.

Hindin, M. J., Kishor, S., and Ansara, D. L. 2008. "Intimate Partner Violence and Couples in 10 DHS Countries: Predictors and Health Outcomes". DHS Analytical Studies No. 18. Calverton, MD USA: Macro International Inc.

ICF Macro 20I0. "Gender and Health Indicators in Ghana: Data from the 2008 Demographic and Health Survey". Calverton, Maryland, USA: ICF Macro.

Kishor, S., and Bradley, S. E. K. 20I2. "Women's and Men's Experience of Spousal Violence in Two African Countries: Does Gender Matter?", DHS Analytical Studies No. 27 Calverton, MD USA: ICF International.

Kishor, S., and Johnson, K. 2004. "Profiling Domestic Violence - A Multi-Country Study”. Calverton, USA: ORC Macro.

National Population Commission 2004. "National Population Policy for Sustainable Development". Abuja, Nigeria: National Population Commission.

National Population Commission and ICF Macro 2009. "Nigeria Demographic and Health Survey 2008". National Population Commission and ICF Macro. Abuja, Nigeria.

Nyamayemombe, C. V., Mishra, S., Rusakaniko, C., Benedikt, Gwazame, M., and Mukweza, P. 2010. "The Association between Violence against women and HIV: Evidence from a National Population-Based Survey in Zimbabwe". 
Zimbabwe Working Papers, No. 4.

Calverton, Maryland, USA: ICF Macro.

Okemiri, E. B., and Adekola, G. 2012. "Violence Against Women in Ikwerre Ethnic Nationality of Nigeria: Challenges for Gender Equity and Development", Studies in Sociology of Science $3(2): 6-12$.

Omoluabi, E., Aina, O. I., and Attanasso, M. O. 2014. “Gender in Nigeria's development discourse: relevance of gender statistics", African Population Studies 27 (2) Supp: $\quad$ 372-385.

Owoaje, E. T., and OlaOlorun, F. M. 2012. "Women at Risk of Physical Intimate Partner Violence: A Cross Sectional Analysis of a Low-income Community in Southwest Nigeria", African Journal of Reproductive Health 16(I): 43-53.

Population Reference Bureau 2010. "Gender-Based Violence: Impediment to Reproductive Health". Retrieved August 5, 2013 from www.prb.org/igwg_media_impediment_to_RH.p df

StataCorp. 2009. "Stata: Release II. Statistical Software". College Station, Texas: StataCorp., LP. Stata

Stewart, H., Sommerfelt, E., Borwankar, R., Oluwole, D., Fogg, K., and Goings, S. 2010. "Domestic violence against women in subSaharan Africa: Associations with maternal health". Presented in commemoration of 16 Days of Activism against Gender Violence 2010. Retrieved August 25, 2013 from www.igwg.org/igwg_media/domestic_violence_p resentation.pdf .

Straus, M. A. 1979. "Measuring Intrafamily Conflict and Violence: The Conflict Tactics (CT) Scales", Journal of Marriage and Family 4I(I): 7588. Retrieved August 24, 2013 from www.jstor.org/stable/35I733?seq $=6$.

Tuladhar, S., Khanal, K. R., Lila, K. C. Ghimire, P. K., and Onta, K. 2013. "Women's Empowerment and Spousal Violence in Relation to Health Outcomes in Nepal: Further analysis of the 201 I Nepal Demographic and Health Survey". Calverton, Maryland, USA: Nepal Ministry of Health and Population, New ERA, and ICF International.
United Nations 1995. "Beijing Declaration and Platform for Action, Fourth World Conference on Women". 15 September 1995, A/CONF.I77/20 (1995) and A/CONF. I77/20/Add.I (1995). Retrieved August 24, 2013 from http://www.refworld.org/docid/3dde04324.html

United Nations Fund for Population Activities 2012. "Achieving Universal Access to Reproductive Health Services in Nigeria" UNFPA, Abuja, Nigeria.

Uwameiye, B. E. and Iserameiya, F.E. 2013. "Gender Based Violence against Women and its Implication on the Girl Child Education in Nigeria”. International Journal of Academic Research in Progressive Education and Development 2(I): 219-226.

World Health Organization 2002. "World Report on Violence and Health". Geneva: WHO. Retrieved August 24, 2013 from

http://whqlibodoc.who.int/hq/2002/924I5456I5. pdf

World Health Organization 2005. "WHO Multicountry Study on Women's Health and Domestic Violence against Women". Geneva: WHO.

World Health Organization 20I2. "Understanding and addressing violence against women". Retrieved June 25, 2013 from http://apps.who.int/iris/bitstream/10665/77432/1/ WHO RHR 1236 eng.pdf

Yusuf, O. B., Arulogun, O. S., Oladepo, O., and Olowokeere, F. 20II. "Physical violence among Intimate partners in Nigeria: A multi level analysis", Journal of Public Health and Epidemiology 3(5): 240-247. 